\title{
INSEGURANÇA E TRIBUTAÇÃO: A SOCIEDADE CONTEMPORÂNEA E A SUA NOVA COMPREENSÃ O DO FENÔMENO JURÍDICO-TRIBUTÁRIO
}

\section{INSEGURIDAD Y TRIBUTACIÓN: LA SOCIEDAD CONTEMPORÁNEA Y SU NUEVA COMPRENSIÓN DEL FENÓMENO JURÍDICO-TRIBUTARIO}

\author{
${ }^{1}$ Antonio Alves Pereira Netto \\ ${ }^{2}$ Manoel Cavalcante de Lima Neto
}

\section{RESUMO}

Este trabalho tem como objetivo estudar, a partir de elementos sociológicos, a justificação do poder de tributar na sociedade contemporânea. Tem como hipótese de trabalho a ideia de que o Direito Tributário não deve ser entendido como um ramo de "pureza teórica", a reger-se isoladamente por valores e princípios próprios. Defende-se que o Direito Tributário tem passado por uma gradual reformulação de seus conceitos, em razão das novas funções atribuídas ao Estado no contexto da sociedade contemporânea, marcada pela evolução constante que requer uma nova forma de adaptação do direito para regular tais situações em todos os níveis, que decorre do avanço da tecnologia e da globalização. Utiliza a pesquisa jurisprudencial e bibliográfica para demonstrar os efeitos da chamada "sociedade de risco" no papel do Estado e, mais especificamente, no discurso de legitimação do poder de tributar junto ao corpo social.

Palavras-chave: Sociedade de risco, Poder de tributar, Globalização

\begin{abstract}
Este trabajo tiene como objetivo el estudio, a partir de elementos sociológicos, de la justificación del poder tributario en la sociedad contemporánea. La hipótesis del trabajo es la idea de que el Derecho Tributario no debe ser entendido como una rama de pureza teórica, fundamentado apenas en valores y principios propios. Sostenemos que el Derecho Tributario ha pasado por una gradual reformulación de sus conceptos, en razón de las nuevas funciones asignadas al Estado en el contexto de la sociedad contemporánea, la cual se caracteriza por la inseguridad en todos sus significados, consecuencia, en última análisis, del avanzo de la tecnología y de la globalización. La investigación utiliza jurisprudencias y bibliografías como base para demostrar los efectos de la llamada sociedad del riesgo en la labor del Estado y, específicamente, en el discurso de legitimación del poder tributario ante el cuerpo social.
\end{abstract}

Keywords: Sociedad del riesgo, Poder de tributar, Globalización

\footnotetext{
${ }^{1}$ Especialista em Direito Tributário pelo Instituto Brasileiro de Estudos Tributários, IBET - São Paulo - SP , (Brasil). Professor visitante em cursos de graduação e pós-graduação. E-mail : antonioattn@ gmail.com

${ }^{2}$ Professor adjunto da Universidade Federal de Alagoas, UFAL - AL, (Brasil). Juiz de direito - Tribunal de Justiça do Estado de Alagoas - AL, (Brasil). E-mail: leonam1@uol.com.br
} 


\section{INTRODUÇÃO}

Nem o mais formalista dos juristas nega que, ao menos em última análise, o direito é um objeto cultural. Por isso, o direito também não escapa do seu próprio tempo. Não é difícil verificar como a evolução do pensamento social repercute de forma geral sobre todas as formas de expressão e inter-relação humana. Pode-se afirmar que avanços na filosofia deságuam em correspondentes formas de manifestações artísticas e políticas, por exemplo. Neste processo, em alguns momentos é difícil afirmar com convicção qual o fator original para a cadeia de transformações que eventualmente se sucede. Interessará aqui, de início, verificar como se dão as novas formas de organização social e cultural a partir de grandes eventos, como desastres naturais, guerras ou o avanço da tecnologia, que têm profundamente afetado a sociedade contemporânea.

Os sociólogos e os estudiosos das mais variadas áreas têm debatido sobre o perfil da sociedade atual, sempre apontando no sentido da fluidez das suas relações, geralmente como produto decorrente do progresso científico, do excesso de informação e da globalização.

No mesmo contexto, pode-se dizer que a sociedade tem se sujeitado a situações que a expõe a incertezas e a possibilidades de riscos cada vez maiores, tornando marca do tempo presente o constante sentimento de insegurança. Fala-se em insegurança urbana, social, amorosa, ambiental, sanitária, política, econômica etc.

O presente trabalho, pois, destina-se a fazer uma análise ampla do perfil dessa sociedade contemporânea global, buscando seus traços mais característicos e determinantes, utilizando-se, para tanto, das análises feitas por sociólogos já consagrados. Posteriormente, será analisada a jurisprudência do Superior Tribunal Federal a fim de que seja demonstrado como a insegurança sistêmica que acomete a sociedade contemporânea, influenciada pelos riscos sociais e pela globalização, tem modificado diretamente os institutos do Direito Tributário. Com isso, pretende-se demonstrar que o Direito Tributário não é ramo isolado da ciência jurídica e não está imune aos fluxos e refluxos dos câmbios experimentados no âmbito da sociedade, defendendo-se que seu estudo deve estar em consonância com os diversos aspectos sociais que atualmente moldam a sua função. Em verdade, acredita-se que o poder de tributar vem passando por uma completa reformulação de sua função e legitimação social, o que repercute em todos os demais institutos jurídicos que lhe são decorrentes, alterando, assim, a compreensão sobre o fenômeno jurídico-tributário no Brasil. 
Para alcançar tais objetivos, desenvolve-se pesquisa bibliográfica e jurisprudencial, visando sedimentar o entendimento sobre as mudanças que tem enfrentado a sociedade contemporânea, o que se dá para compreender, mediante raciocínio comparativo e indutivo, como tais câmbios têm afetado o discurso de justificação das funções que se esperam do Estado e, pois, do Poder de Tributar.

\section{CONTEMPORANEIDADE, SEGURANÇA, RISCOS E GLOBALIZAÇÃO}

Sem espaço para dúvidas, a segunda metade do Século XX proporcionou eventos determinantes para a caracterização da sociedade atual. Seguramente, não é a intenção deste trabalho descer a todos os inúmeros fatores envolvidos nos processos de mudança social ocorridos desde o fim da Segunda Guerra. Em verdade, nem os grandes sociólogos e filósofos chegaram sequer a um consenso sobre como denominar tal período, além de que há diversas explicações sobre os diferentes movimentos ocorridos nas diferentes sociedades (fala-se em pósmodernidade dos países centrais, modernidade tardia dos países periféricos, entre outras complexas e confusas conceituações e classificações) ${ }^{1}$. Para compreendê-los, seria necessário um estudo mais aprofundado, incompatível com os limites de um artigo.

Interessa aqui abordar brevemente os elementos sociais que marcam a era presente, para que posteriormente se discuta como o direito tem reagido a eles, em especial o Direito Tributário e as razões que atualmente se extraem da tributação.

Pode-se dizer que uma das principais heranças da Segunda Guerra Mundial foi a evolução tecnológica. Veja-se a computação, a internet, a conquista do espaço e todos os demais avanços científicos que são relacionados. A velocidade da informação, a facilidade de locomoção, a prática do consumismo, todos esses são fatores que podem ser encontrados, em maior ou menor medida, em todo o mundo, e que vem, gradualmente, cedendo o espaço do local em favor do internacional. Eis a chamada globalização, entendida ainda como um processo ou um fenômeno em desenvolvimento. Aponta-se que o mercado econômico internacional é o motor responsável pela intensificação desse fenômeno ${ }^{2}$.

Boaventura de Sousa Santos fala que desde o Século XIX a sociedade tem passado por três distintos períodos. O primeiro, que chama de "capitalismo liberal", é marcado pelo predomínio da filosofia política liberal, pelo desenvolvimento do mercado e por um Estado minimamente intervencionista, preocupado com a acumulação do capital e com a dominação política. É uma época de graves contradições, ante a dificuldade de por em prática todos os ideais que lhe deram origem (solidariedade e identidade; liberdade e igualdade são exemplos). O 
direito é dominado por um formalismo extremado e guiado por uma ética liberal, que foca na responsabilização do indivíduo ${ }^{3}$.

O segundo período, chamado de "capitalismo organizado", se desenvolveu no sentido de compor as graves contradições do período anterior, e se caracterizou pela criação do "Estadoprovidência", responsável pela regulação econômica e forte atuação social, gerindo assuntos de interesse da coletividade, como a saúde, educação e habitação, e prevalecendo os princípios do Estado e da comunidade. O Estado se posiciona como um agente ativo de transformações sociais e econômicas, mas também está acometido por contradições sistêmicas: “[...] na forma política do Estado que ao mesmo tempo que penetra mais profundamente na sociedade fá-lo através de soluções legislativas, institucionais e burocráticas que o afastam progressivamente dos cidadãos [...]"4. No campo do direito, esse movimento se reflete numa ordem jurídica dogmática e formalista, teoricamente desapegada de carga axiológica ou política. Trata-se de uma época de valorização do conhecimento científico e no direito se destaca a formulação da teoria pura do direito $^{5}$.

O terceiro período, o atual, é descrito como uma ordem totalmente distinta e complexa, chamada por Boaventura de "capitalismo desorganizado", que se dá em resposta à tendência de forte intervenção estatal. Explica o autor que o modelo político atual é caracterizado por uma desregulamentação global da vida econômica, social e política, impulsionado pela explosão do mercado mundial, pelo surgimento de empresas multinacionais, pela prevalência do princípio do mercado sobre o princípio do Estado e da comunidade. Nas palavras do autor: "O Estado nacional parece ter perdido em parte a capacidade e em parte a vontade política para continuar a regular as esferas da produção e da reprodução social [...]; a transnacionalização da economia [...] transformam o Estado numa unidade obsoleta [...]"6.

Neste momento, o Estado já não consegue cumprir todas as responsabilidades assumidas no período anterior. É uma época marcada pelo avanço científico e tecnológico, mas também por profundas mudanças e contradições. O Estado não se mostra mais capaz de garantir a regulação social diante da extrema volatilidade das relações econômicas, políticas e sociais. O autor afirma ainda que o excesso de informação, de possibilidades, de escolhas, acaba contraditoriamente submetendo a sociedade capitalista a uma condição de passividade, diante da impossibilidade de gerir tantos avanços. Esse quadro é a grande questão que aqui se quer chamar a atenção. Veja-se:

[...] a modernização científico-tecnológica e neoliberal alastra hoje, paradoxalmente, na mesma medida em que alastra a sua crise, certificada por aquilo que parecem ser as 
suas consequências inevitáveis: o agravamento da injustiça social através do crescimento imparável e recíproco da concentração da riqueza e da exclusão social, tanto a nível nacional como a nível mundial; a devastação ecológica e com ela a destruição da qualidade e mesmo da sustentabilidade da vida no planeta.

$[\ldots]$

A modernidade confinou-nos numa ética individualista, uma micro-ética que nos impede de pedir, ou sequer pensar, responsabilidades por acontecimentos globais, como a catástrofe nuclear ou ecológica, em que todos, mas ninguém individualizadamente parece poder ser responsabilizado (Apel, 1984). Este impasse ético reside em que se, por um lado, a microética liberal é inadequada para responder adequadamente às exigências éticas da nova situação em que nos encontramos, por outro lado, não foi ainda substituída por uma macroética capaz de conceber ao nível da escala planetária ${ }^{7}$.

Conforme se vê, a sociedade atual já não consegue administrar seus próprios avanços, de modo que o direito não mais oferece um modelo de solução ou responsabilização capaz de atender às novas formas de insegurança social. Após o acidente nuclear de Chernobyl, na Ucrânia, o sociólogo alemão Ulrich $\operatorname{Beck}^{8}$ criou a expressão "sociedade de risco" para se referir à insegurança típica dos tempos atuais.

O risco, que era visto só como uma ameaça da natureza até o Século XIX, passou a ser entendido como um produto do homem, decorrente da instalação de complexos industriais ou nucleares, pelo surgimento dos alimentos transgênicos, ou qualquer ação que possa desencadear, de forma imprevisível, danos incalculáveis à sociedade. O avanço científico, por exemplo, é apontado como o culpado pelas mudanças climáticas, pelas inundações, pelo buraco na camada de ozônio, enfim, pelo conjunto de graves danos em potencial a que a sociedade está sujeita e que sequer pode prever a origem, nem definir quem é responsável por eles ${ }^{9}$.

Os riscos, assim como a sociedade contemporânea (ou, segundo alguns, pós-moderna), seguiriam uma lógica ambivalente, no sentido de que "cada medida adotada para a solução de problemas de determinado grupo de pessoas traz em si mesma a criação de problemas para outro grupo de pessoas" ${ }^{10}$. Surge um ciclo desenfreado: novos problemas demandam novas soluções, que, por sua vez, geram novos problemas (veja-se o problema da fome, da suposta solução pela criação de alimentos transgênicos, que aumenta a produtividade agrícola e diminui os preços, mas são acusados de provocarem riscos alimentares, em razão do desconhecimento dos efeitos à saúde no consumo em longo prazo).

Além disso, torna-se muito importante observar que a ideia de risco é exclusivamente uma criação humana, um conceito subjetivo acerca da probabilidade da ocorrência de um dano, o que não se confunde com o próprio dano. Pode-se afirmar, assim, que o risco é, também, um objeto cultural, que pode ser moldado, aceitado ou agravado conforme a sociedade se determine 
com relação a certo evento. "O risco, objeto social, define-se como a percepção do perigo, da catástrofe possível"11.

Ocorre que a complexidade dos progressos humanos se espraia por todas as áreas, sendo assim, a noção de risco também é generalizável: fala-se em risco ambiental, alimentar, urbano, sanitário, político, econômico, financeiro, etc. Por ser necessariamente uma construção social, a globalização assume um papel relevante na sua disseminação e homogeneização mundial. A transnacionalização da economia, junto com a dependência dos países emergentes ao capital especulativo, geram, por exemplo, uma forte sensação de risco social, migratório, ou de segurança pública. Nesse sentido, a noção de risco passa a adquirir um forte viés político ${ }^{12}$.

A questão ultrapassa a racionalidade científica ou a criação de novos métodos que diminuam qualquer fator potencialmente lesivo que se apresente, pois o risco está ligado à perda de segurança de modo amplo: os fatores de dano são incalculáveis e irregulares, dada a multiplicidade e imprevisibilidade das variáveis envolvidas.

Isso, por consequência, afeta diretamente a função do Estado. Nesse novo momento, principalmente nos países centrais, a antiga discussão sobre a equânime distribuição das riquezas, no ambiente de uma sociedade carente, cede lugar à discussão sobre a equânime distribuição dos riscos, agora em sociedades com desenvolvimento científico-tecnológico. ${ }^{13}$

Nos países periféricos, ambas as questões coexistiriam, ante a alegada convivência de distintos momentos históricos (a suposta transmodernidade) ${ }^{14}$.

A insegurança é a grande marca do tempo presente, em qualquer das suas dimensões. Bauman fala que "a sociedade moderna [...] foi construída sobre a areia movediça da contingência: a insegurança e a ideia de que o perigo está em toda parte são inerentes a essa sociedade" 15 . Na sociedade de riscos, o ideal da igualdade (típica da sociedade industrial) é substituído pelo ideal da segurança. O grito de "medo" ocupa o lugar do grito de "fome"16.

Todavia, Boaventura de Sousa Santos afirma que "o inconformismo perante estas consequências combinado com uma crítica aprofundada da epistemologia da ciência moderna está hoje a contribuir para a emergência de um novo paradigma" ${ }^{17}$. Segundo ele, "[...] começa a emergir um novo jus-naturalismo assente numa nova concepção dos direitos humanos e do direito dos povos à autodeterminação, e numa nova ideia de solidariedade, simultaneamente concreta e planetária" ${ }^{18}$.

Nas palavras de Beck, "En este sentido, el tipo de la sociedad del riesgo marca una época social en la que la solidaridad surge por miedo y se convierte en una fuerza política"19. 
Como a eliminação do risco parece ser algo inalcançável, passa-se a geri-lo, quantificá-lo, criando-se métodos de redistribuição solidária, objeto no qual o Estado assume papel de suma importância, alterando sua função no quadro da sociedade contemporânea ${ }^{20}$.

Esse conjunto de fenômenos, cumulado com a flexibilização da soberania estatal decorrente da globalização (em razão do prevalecimento do poder econômico sobre o político), tem feito com que o Estado perca progressivamente sua função reguladora, expedidora de regras para todo o ordenamento jurídico e passe a ser mero protetor de valores e direitos fundamentais, com conteúdo aberto e forte carga axiológica. Por uma nova demanda da sociedade, fala-se numa reconstrução do conceito de segurança jurídica, pois agora cabe ao Estado proteger a sociedade dos riscos sociais ${ }^{21}$. A segurança já não está mais exclusivamente vinculada à ideia de liberdade, que exige uma abstenção estatal, assim como a atuação positiva que se espera do Estado não é no nível do intervencionismo econômico, mas no gerenciamento e distribuição dos riscos.

\section{A JUSTIFICAÇÃO DO PODER DE TRIBUTAR EM MEIO AO RISCO}

Conforme demonstrado, a época atual é composta por novos problemas, novas contradições e novos anseios sociais. A globalização e a consequente preponderância do poder econômico internacional sobre o político local tem flexibilizado a soberania estatal e, por decorrência, fica reduzido o caráter autoritativo e coercitivo do direito, sendo crescente a ideia de autorregulação e surgindo o que se tem chamado de "soft law" - um direito não estatal e flexível, apto a se adequar às rápidas mudanças do mercado ${ }^{22}$.

A globalização pela liberdade de circulação de capitais, bens e mercadorias também influencia a soberania fiscal que numa economia aberta limita a criação e manutenção de tributos por interesse apenas do próprio ente político, instaurando uma concorrência fiscal que remete para o problema da insuficiência de receita fiscal dela decorrente ${ }^{23}$.

É dizer que a integração dos mercados traz consigo a "internacionalização dos riscos, fazendo com que eventuais prejuízos se alastrem por toda a sociedade global, como no caso das recentes crises financeiras" 24 .

Afinal, o mesmo avanço científico e tecnológico que possibilita a ocorrência da globalização é responsável por catástrofes como o acidente da usina nuclear de Chernobyl, assim como por outros danos incalculáveis, irreparáveis e de difícil responsabilização, acometendo a 
sociedade contemporânea a uma extrema insegurança. Como resposta, o Estado é chamado a distribuir de maneira equânime estes riscos, gerindo-os nessa que corresponde a uma nova concepção de segurança e segurança jurídica.

Como já delineado linhas acima, o Estado acaba por assumir uma nova função frente ao corpo social. Essa alteração, todavia, implica na alteração de conteúdo de vários de seus institutos, que passam a receber nova utilidade e interpretação pelos tribunais.

A hipótese que instiga esse trabalho é a de que, para além de uma mera modificação teórica, as mudanças ocorridas têm produzido seus efeitos inclusive na seara do Direito Tributário e que, nela, já é possível visualizar com claridade a modificação no conteúdo e na extensão dos valores que lhe regem, o que implica numa alteração substancial na compreensão do poder de tributar e dos direitos fundamentais dos contribuintes. Cuida-se de uma completa reformulação de conceitos que, ao que se acredita, está em andamento e que os fenômenos sociais expostos no tópico anterior estariam produzindo uma influência direta.

Para demonstrar a tese, será tomada como primeira referência a decisão proferida pelo Supremo Tribunal Federal no julgamento da Ação Direta de Constitucionalidade n ${ }^{\circ} 3.105$.

Antes disso, é interessante verificar que os três períodos da evolução da sociedade, expostos por Boaventura de Sousa Santos no tópico anterior, se alinham com as três sucessivas justificativas teóricas ao poder de tributar, expostas por Paulo Caliendo ${ }^{25}$. Na primeira, que chama de "conceitual", o poder de tributar é a expressão de um poder de império (jus imperii) sobre os indivíduos. Há uma clara divergência entre Estado e indivíduo e a tributação é o comando coercitivo para que parte da riqueza privada seja transferida para o Estado. Nesse momento, a norma é presumidamente justa em função da autoridade que a emite e vigora uma concepção individualista do sujeito. O poder de tributar corresponde a uma imposição de poder do Estado sobre o indivíduo.

Na segunda justificativa, chamada de "normativista", o poder de tributar se justifica pelo exercício de uma competência normativa, na qual a sua legitimidade é aferida pela observância dos procedimentos previamente estabelecidos. O debate jurídico se dá em função da compatibilidade estrutural-sintática das normas com o ordenamento jurídico e as relações tributárias se estabelecem entre sujeitos de direito (contribuinte e fisco). Essa visão de sistema tributário é vazia de qualquer valor ou conteúdo ético, adequada à revolução do pensamento jurídico ocorrida pela teoria pura de Kelsen. 
No terceiro momento, onde vigora uma concepção "sistemática" do direito, o poder de tributar estaria justificado no sentido da concretização dos valores de liberdade e igualdade. Neste momento, a tributação é exercida como um instrumento para a realização da justiça, de modo que a imposição tributária (em abstrato), assim como todas as relações jurídico-tributárias (em concreto), devem ser guiadas pelo ideal da justiça fiscal, ou seja, pela compatibilidade material (ética) com os valores do sistema jurídico.

Resume o mencionado autor afirmando que "podemos, assim, definir a história da tributação como a história que leva o indivíduo da servidão à cidadania" ${ }^{\text {26 }}$. Essa mudança pode ser constatada pelas alterações substanciais que os institutos de Direito Tributário vêm sofrendo em razão do modelo constitucional atualmente adotado. Mas não é só isso, pode-se dizer, ainda, que a jurisprudência brasileira tem contribuído de forma determinante para que, ao longo dos últimos anos, seja acentuado o conteúdo moral presente nas normas tributárias.

Essa sistemática, todavia, implica numa grande abertura semântica e axiológica, deixando o direito mais vulnerável às influências dos interesses sociais. É nesse ponto que será possível visualizar que, em resposta aos anseios de que o Estado brasileiro assuma a postura de gestor dos riscos sociais, o Supremo Tribunal Federal exara um julgado no qual é fácil identificar a mudança ocorrida no conteúdo do princípio da solidariedade, conforme mencionado por Boaventura no tópico anterior.

No julgamento da Ação Direta de Inconstitucionalidade $\mathrm{n}^{\circ}$ 3.105-DF, o S upremo Tribunal Federal apreciou a constitucionalidade do art. $4^{\circ}$, caput, da Emenda Constitucional $n^{\circ} 41 / 2003$, que cria a contribuição social incidente sobre os proventos de aposentadoria e pensões. A doutrina nacional se posicionou de forma determinante pela inconstitucionalidade do novo tributo criado, pois estaria violando o espectro de competências e imunidades definidas pelo poder constituinte originário, correspondendo a grave ofensa aos direitos fundamentais dos contribuintes, que não podiam se ver sujeitos a uma tributação desconforme com as garantias constitucionais.

Segundo Humberto Ávila, ainda que a Constituição Federal de 1988 aponte como objetivo fundamental da república (art. $3^{\circ}$, I) a construção de uma sociedade solidária e que esse dispositivo possa ser utilizado, em caráter abstrato, para justificar de maneira ampla o poder de tributar, jamais poderia ser suscitado como fundamento exclusivo e direto para a instituição ou a manutenção de um tributo específico. Isso ocorreria porque a par dos princípios constitucionais, o texto fundamental também dispõe de regras estruturais que estabelecem competências tributárias e limitações materiais à fixação das hipóteses de incidência. Assim, por 
serem disposições normativas de mesma estatura constitucional, o princípio da solidariedade social (de conteúdo abstrato) não poderia ser interpretado de modo a confrontar as regras constitucionais, que são mais específicas ${ }^{27}$.

Para os fins aqui propostos, interessa colacionar alguns trechos do voto do Ministro César Peluso, que foi o voto vencedor na resolução da questão constitucional referida:

[...] o regime previdencial deixou de ser eminentemente contributivo para se tornar contributivo e solidário, como se infere límpido à redação que emprestou ao art. 40, caput, da Constituição da República.

Ditaram essa transmutação do regime previdencial, entre outros fatores políticos-legislativos, o aumento da expectativa de vida do brasileiro e, consequentemente, do período de percepção do benefício, bem como a preocupação permanente com o dito equilíbrio financeiro e atuarial do sistema, tudo isso aliado à queda da taxa de natalidade e à diminuição do acesso aos quadros funcionais públicos. Essa equação, de crescente pressão financeira sobre uma estrutura predominantemente solidária e distributiva, conduziria a inexorável desproporção entre servidores em atividade e aposentados, tendendo ao colapso de todo o regime. Essa mesma tendência, observada já à época das Emendas $n^{\circ} 3 / 93$ e $n^{\circ} 20 / 98$, é que esteve à raiz das transformações do regime eminentemente solidário, em vigor antes da $\mathrm{EC} \mathrm{n}^{\circ}$ 03/93, para outro que, como regime contributivo e solidário, adotava a contribuição dos servidores ativos [...] e, depois, para regime predominantemente contributivo, o da $\mathrm{EC} \mathrm{n}^{\circ} 20 / 98$.

A crise estrutural dos sistemas previdenciários estatais não é fenômeno recente, nem circunscrito ao país. Relatório do Banco Mundial, sob o título de "Averting the Old Age Crisis, Policies to Protect the Old and Promote Grownth", de 1994, já revelava tratar-se de persistente problema global. São patentes a atualidade e a pertinência do diagnóstico: [suprimido]

Esse inquietante quadro social, econômico e político, em que, sob juízo isento e desapaixonado, não se pode deixar de situar o país, interessa ao Direito, porque subjaz como fonte da razão normativa (ratio iuris) à aprovação da $\mathrm{EC} \mathrm{n}^{\circ}$ 41/2003, que estendeu aos servidores públicos inativos o ônus de compartilhar o custeio do sistema previdenciário. Conforme já notamos, a vigente Constituição da República moldou um sistema de seguridade social baseado nos objetivos ou princípios capitulados no art. 194, parágrafo único:

$[\ldots]$

O art. 195, caput, firmou outro princípio sistemático fundamental, agora para definição do alcance das fontes de custeio, preceituando que "a seguridade social será financiada por toda a sociedade, de forma direta e indireta", e, no $\S 5^{\circ}$, editou a chamada regra de contrapartida, que dispõe: "nenhum benefício ou serviço da seguridade social poderá ser criado, majorado ou estendido sem a correspondente fonte de custeio total".

$[\ldots]$

Mas arguem, em suma, os requerentes que seria inválida tal imposição, e sua invalidez decorreria da ausência de causa suficiente para a contribuição: (i) ofensa ao direito adquirido (ii) e ao princípios da irredutibilidade dos vencimentos (iii) de bitributação em relação ao imposto de renda (iv) e de lesão ao princípio da isonomia (v).

[...]

Enganam-se ainda ao pressupor ao regime previdenciário constitucional, como premissa indisfarçável do raciocínio, um cunho eminentemente capitalizador e contributivo, entendido segundo a matriz da relação jurídica de direito privado, de perfil negocial ou contratual, que é domínio dos interesses patrimoniais particulares e disponíveis.

$[\ldots]$ 
O regime previdenciário público tem por escopo garantir condições de subsistência, independência e dignidade pessoais ao servidor idoso, mediante o pagamento de proventos da aposentadoria durante a velhice, e, conforme o art. 195, da Constituição da República, deve ser custeado por toda a sociedade, de forma direta e indireta, o que bem poderia chamar-se princípio estrutural da solidariedade $^{28}$ (Grifo nosso).

Ora, o julgado colacionado demonstra que os riscos sociais sistêmicos estão na pauta de atenções do Supremo Tribunal Federal, que emitiu um julgado surpreendente, ao justificar a constitucionalidade, ou seja, a validade de uma imposição tributária, para além das regras competenciais dispostas no texto fundamental, mas verdadeiramente analisando o contexto social e a nova significação do princípio da solidariedade, expondo entendimento no sentido de que cabe à sociedade por completo, de forma conjunta, distribuir os ônus sociais, de maneira que sejam evitados os riscos decorrentes do avanço científico típico da contemporaneidade.

No caso específico, conforme transcrito, as causas sociais em questão foram: o aumento da longevidade dos cidadãos e a redução da taxa de natalidade, o que implicam num menor número de contribuintes para o sistema de previdência social, enquanto que tem aumentado o número de beneficiários não contribuintes. Vislumbrou o STF a possibilidade de "colapso de todo o regime". Além disso, é enfático ao afirmar que tal circunstância não está adstrita ao Brasil, antes é um problema que acomete toda a sociedade global e faz menção a documento técnico internacional que relata esse quadro social (aqui suprimido por não ser indispensável à compreensão da tese e por razões de praticidade).

Verifica-se a riqueza do mencionado julgamento para um estudo com viés sociológico pelo fato de que as razões sociais a motivar a decisão jurídica já são expressamente trazidas no seu discurso justificador, facilitando a comparação e a análise sociológica com o panorama social da modernidade, já exposto na seção anterior. Ante a imanência dos riscos das mais diversas ordens, a solidariedade tem sido o meio e a justificação que a sociedade tem encontrado para legitimar uma distribuição equânime dos riscos sociais, os quais podem ocasionar um dano generalizado e não quantificável (no caso em análise, o colapso do sistema previdenciário nacional, que certamente assumiria proporções catastróficas).

O que se vê, portanto, é uma extensão substancial do princípio da solidariedade, que passa de "objetivo fundamental da república", de enunciado de teor axiológico a guiar teleologicamente o sistema jurídico, a um enunciado capaz de legitimar diretamente uma 
competência tributária não prevista pelo poder constituinte originário, numa indubitável extensão de sentido.

A mudança aqui relatada encontra justificação no fato de que o momento vivenciado estaria nos exigindo esforços para solucionar problemas que anteriormente não existiam. Nesse sentir, Ricardo Lobo Torres bem pontua que a tributação na sociedade de riscos assume funções e fundamentos mais amplos em razão do "redesenho do relacionamento entre as atribuições das instituições do Estado e da própria sociedade" ${ }^{29}$, com efeito direto, inclusive, no conteúdo da legalidade tributária.

Essa nova conformação estaria configurada por uma cadeia de subsidiariedades na responsabilização pelos riscos da vida em sociedade. Assim, os indivíduos seriam primariamente responsáveis pelo seu próprio bem estar, todavia, quanto mais difuso o risco ou mais difícil sua completa assunção pelo particular, este passaria à coletividade e, subsequentemente, a todo o Estado, numa verdadeira socialização das dificuldades típicas da vida contemporânea, atentando para uma equidade que toma em conta a carga da contribuição com o grau do risco a que se sujeita o grupo social onerado.

[...] Por isso mesmo, aqui e no estrangeiro, a legislação vem criando 'taxas de fiscalização' ou 'contribuições especiais' para a cobertura dos riscos, cabendo o seu pagamento às pessoas envolvidas pela equação financeira dos respectivo contratos $[\ldots]$ ou na prática de atividades potencialmente arriscadas.

Os riscos da segurança nacional e da segurança pública devem necessariamente ser assumidos pelo Estado, que se financiará através de impostos extraídos da sociedade com base nos princípios da legalidade e da capacidade contributiva.

Mas os riscos da existência (doença, velhice, desemprego, etc.) e os riscos ambientais deverão ser suportados financeiramente pela própria parcela da sociedade que transferir ao Estado o ônus da proteção ${ }^{30}$. (Grifos do autor)

Tal compreensão advém do reconhecimento de que "os riscos não podem ser eliminados, mas aliviados por mecanismos de segurança social, econômica e ambiental”, o que evidencia que a decisão exarada pelo Supremo Tribunal na ADI n. 3.105-DF está em consonância com as mudanças experimentadas por alguns institutos jurídicos, conforme explana a doutrina preocupada com as transformações sociais aqui estudadas.

Ainda no escólio de Ricardo Lobo Torres, a própria legalidade tributária estaria submetida a um necessário "equilíbrio entre segurança e justiça", ante o desafio de a tributação acompanhar com efetividade a necessidade de cobertura das novas vulnerabilidades sociais, no que aponta como exemplo a contribuição social destinada a cobrir os riscos de acidentes de trabalho (RAT), que gradua suas alíquotas de acordo com os conceitos de risco leve, médio ou 
alto, mas que os regulamenta e classifica as empresas por meio de ato infra legal, de acordo com as suas atividades preponderantes ${ }^{31}$. Mesmo assim, o mecanismo não caracterizaria ofensa à legalidade tributária, considerando que a gradação do potencial de risco de acidente de trabalho levaria em conta diversos fatores, demandando estudos estatísticos específicos, sempre sujeitos a ligeiras mudanças em razão do avanço tecnológico ${ }^{32}$. Desta forma, mesmo extrapolando os conceitos da "legalidade estrita" e da "tipicidade fechada", a constitucionalidade da medida não restaria afetada, conforme já decidiu o STF no RE 343.446/SC.

Para mais um exemplo, pode-se mencionar a utilização dada ao princípio da segurança jurídica quando do julgamento dos REs 560.626, 556.664 e 559.882. Os recursos foram julgados em conjunto e os ministros foram unânimes em declarar inconstitucionais os arts. 45 e 46, da Lei n. 8.212/91, que fixavam em dez anos os prazos prescricional e decadencial das contribuições previdenciárias. Entendeu-se que havia violação à Constituição, pois se exige Lei Complementar para regular tal matéria, sendo aplicável, portanto, o prazo geral de cinco anos, conforme previsto no Código Tributário Nacional.

A questão sobre a segurança jurídica está na decisão dos ministros de modularem os efeitos da referida declaração de inconstitucionalidade, tolhendo a retroação da medida para aqueles que não tinham ação judicial em curso na data do julgamento. Deste modo, em nome da "segurança jurídica", impediram que os contribuintes que pagaram indevidamente tributos já atingidos pela prescrição ou pela decadência pudessem ser restituídos do indébito tributário, em face do erário federal. O voto do Ministro Gilmar Mendes foi no seguinte sentido:

(...) Estou acolhendo parcialmente o pedido de modulação de efeitos, tendo em vista a repercussão e a insegurança jurídica que se pode ter na hipótese; mas estou tentando delimitar esse quadro de modo a afastar a possibilidade de repetição de indébito de valores recolhidos nestas condições, com exceção das ações propostas antes da conclusão do julgamento.

Ao decidir por essa providência, é flexibilizada até mesmo a concepção de que cada indivíduo só pode ser tributado dentro dos limites materiais e formais previstos no ordenamento jurídico. O STF, ao mesmo tempo em que reconhece a existência de recolhimentos tributários inconstitucionais, decide sumariamente que os contribuintes que até aquela data não haviam ingressado judicialmente com pedidos de repetição de indébito, não teriam direito à restituição. Convalida, portanto, uma tributação inconstitucional em nome da "segurança jurídica". Embora a sucinta fundamentação não disponha expressamente a respeito, o que se verifica é uma extensão do alcance desse princípio, também de acordo com o que os sociólogos têm levantado acerca da reconstrução do papel do Estado e da Segurança Jurídica. 
Veja-se que, tradicionalmente, a segurança jurídica é levantada como argumento em favor dos cidadãos, uma vez que, numa lógica de conflito de interesses entre Estado e indivíduo, este sempre se encontrou submetido ao poder daquele, sendo o indivíduo o verdadeiro titular da segurança jurídica, afinal, as disposições normativas derivariam unilateralmente do próprio Estado, não havendo sentido que se falasse em segurança jurídica dele para ele mesmo.

Principalmente na esfera das relações tributárias, onde recebem grande destaque a liberdade e a propriedade, a segurança jurídica naturalmente adquiriu um forte viés defensivo, de tutela do particular, consagrando concepções mais formalistas do fenômeno jurídico, ao valer-se das restrições sistêmicas como um meio de proteção em face do arbítrio.

Nesse contexto, quando se fala em modulação de efeitos em matéria tributária, o discurso formal se acentua, principalmente considerando a proteção da confiança dos cidadãos junto ao instrumento normativo estatal considerado inválido, para concluir que o mecanismo não teria legitimidade se manejado em desfavor dos contribuintes, conforme se vê:

\begin{abstract}
Recorde-se que a segurança jurídica foi conceituada neste trabalho como normaprincípio que exige dos Poderes Legislativo, Executivo e Judiciário a adoção de comportamentos que contribuam mais para a existência, em benefício dos cidadãos e na sua perspectiva, de um estado de confiabilidade e de calculabilidade do e pelo Direito, com base na sua cognoscibilidade, como instrumento garantidor do respeito à sua capacidade de, sem engano, frustração ou surpresa, plasmar com dignidade o seu presente e fazer um planejamento estratégico juridicamente informado do seu futuro. Prejuízos financeiros decorrentes da cobrança de tributos inconstitucionais não se enquadram, portanto, no conceito de segurança jurídica tal como está posta na $\mathrm{CF} / \mathbf{8 8}^{33}$. (Grifo nosso)
\end{abstract}

O ponto que aqui merece atenção é que o novo papel do Estado na contenção dos riscos sociais pode exigir, tal qual se deu no exemplo trazido, uma medida excepcional em que a manutenção da arrecadação se apresenta como o único meio de garantir a eficácia dos direitos fundamentais, invertendo-se a lógica até então difundida. Cabe frisar que não se trata de prevalência de interesses estatais, mas exigência decorrente da função de segurador atribuída ao Estado.

Essa nova compreensão, demonstrada pelo STF, que aparentemente só tende a se acentuar, denuncia que o mencionado Tribunal entende que no Estado Democrático de Direito há (ou deve haver) uma confluência entre os interesses dos contribuintes e do Estado ${ }^{34}$, afinal a tarefa deste é garantir e concretizar os direitos daqueles. Chega-se a afirmar, portanto, que é um verdadeiro mito a ideia de contraposição entre direitos dos contribuintes e interesses do Estado, "pois a grande questão no direito tributário não é mais a relação vertical entre fisco- 
contribuinte, mas uma relação horizontal entre os vários contribuintes de uma mesma sociedade" 35 .

\begin{abstract}
(...) a ideia de segurança jurídica ganha uma nova dimensão, superando o modelo do Estado Liberal, onde representou a proteção do cidadão contra o poder do Estado, com a ideia de segurança jurídica, e do Estado Social, em que, na eterna busca da Justiça Social, ganhou a feição de seguridade social. No Estado Democrático e Social, marcado pela sociedade de risco, a segurança se traduz em seguro social. De acordo com essa nova dimensão da segurança, o Estado garante proteção aos cidadãos contra os riscos sociais, a partir de 'uma nova comunhão de responsabilidade entre o cidadão e o Estado, ou uma nova comunhão de riscos e chances' ${ }^{36}$.
\end{abstract}

Adicionalmente ao respaldo teórico aqui demonstrado, a atuação do STF em sede de modulação de efeitos se vê amparada em expressa previsão legal (art. 27 da Lei n. 9.8.68/99) que lhe autoriza a proceder decidindo conforme seu entendimento acerca do conceito de segurança jurídica para o caso que se apresente, de modo que desempenharia, no caso concreto, verdadeiro gerenciamento de riscos, ao ponderar diferentes efeitos como a necessidade de ressarcimento pelo erário de vultosas quantias arrecadadas, a dificuldade para as finanças públicas que lhe são decorrentes, os valores já gastos em serviços públicos, a eventual necessidade de majorar a carga tributária para custear a devolução, entre tantos outros possível efeitos, além de necessariamente levar em conta os próprios direitos dos contribuintes, direitos fundamentais que são.

O que se extrai do estudo empreendido é que o Direito Tributário, em razão das manifestações jurisdicionais trazidas, tem sido utilizado como ferramenta para a concretização desse novo papel de Estado protetor e redistribuidor de riscos e não somente de riquezas, como se propôs num modelo anterior. Além disso, que esse ramo do direito está tão sujeito aos fenômenos sociais como todo o fenômeno jurídico, uma vez que é parte integrante deste e, portanto, necessariamente um objeto cultural.

Essa clara constatação diante de recentes julgamentos proferidos pela corte mais alta do país refuta uma tese ainda extremamente formalista no sentido de que esse ramo jurídico está dissociado dos demais e é permeado por uma pureza teórica única, o que se pode concluir tratarse de uma visão defasada sobre o próprio sistema jurídico.

Concepções reducionistas do fenômeno jurídico, inclusive no sentido de que o Direito Tributário deveria ser estudado de forma isolada, em busca de uma pureza conceitual dos seus institutos, com o mínimo de interferência das demais ciências e ramos do direito, embora tenha cumprido um importante papel na sofisticação da teoria jurídico-tributária nacional, já não oferece resposta aos novos problemas enfrentados pela sociedade nesse novo modelo de sistema constitucional. 
Esse modelo estatal exige que a doutrina tributarista abandone a redução de sua análise à estruturação formal das normas e do ordenamento jurídico - restringindo o Direito Tributário a uma espécie de positivismo jurídico kelseniano aplicado - e avance para a funcionalidade do Direito e dos tributos, a serem examinados com base nos valores sociais consagrados na Constituição 37 .

A compreensão da ciência jurídica, em verdade, deve assumir a complexidade de fatores que a envolve, intentando sempre o encontro da adequada sintonia entre sua estrutura e sua função, sem preponderância epistemológica de uma sobre a outra, uma vez que a análise funcional do direito "é chamada a estender o seu olhar a problemas que eram completamente desconhecidos para as teorias gerais do direito orientadas pela análise estrutural do ordenamento jurídico" ${ }^{38}$, pelo fato de que o direito é um subsistema do sistema social, cujo entendimento não pode estar dissociado das relações entre direito e sociedade e de como esta repercute naquele ${ }^{39}$.

Repercutindo diretamente essa nova concepção de Estado e de Direito na razão do poder de tributar, há de se reconhecer uma mudança na fundamentação dos direitos fundamentais dos contribuintes: "a segurança jurídica do contribuinte ganha uma dimensão plural, baseada na aferição da adequação dos critérios legislativos à justiça fiscal e à repartição dos riscos e custos sociais" $" 40$.

Com base nesses parâmetros, é tempo para uma releitura de alguns dos institutos jurídicos do direito tributário, porquanto os exemplos trazidos são apenas de sentido referencial a demonstrar a atualidade das mudanças. Fala-se ainda em novo conteúdo da legalidade, da capacidade contributiva, da concepção de igualdade, assim como dos demais que tenham fundamento num discurso em direitos fundamentais. 


\section{CONCLUSÃO}

A hipótese aqui levantada foi a de que o Direito Tributário não deve ser estudado como um ramo isolado da ciência jurídica, a reger-se por valores e princípios próprios, em nome de uma suposta "pureza teórica". Sustentou-se que o Direito Tributário está passando por uma gradual e completa reformulação em seus conceitos, em reflexo às novas funções que se espera do Estado no contexto da sociedade contemporânea, marcada pela completa insegurança social em todos os níveis.

Atualmente à ciência jurídica não apenas compete a análise do direito no sentido estrutural, mas também funcional, de modo a abrir o Direito Tributário para recepcionar e regular as necessidades sociais assentes que se demonstra na sociedade de riscos, adaptando-o à realidade, essencial função do direito que não deve manter-se num espectro meramente conceitualista.

Para comprovar a assertiva, foi feita exposição panorâmica acerca do perfil da sociedade contemporânea desde a segunda metade do Século XX. Viu-se que o excessivo progresso tecnológico-científico tem implicado numa nova crise social, a crise de segurança. Os avanços tecnológicos, aliado à globalização, tem sujeitado a população mundial a riscos até então impensáveis, como os desastres nucleares ou as catástrofes naturais, que têm sua causa atribuída a uma ação humana (mudanças climáticas, buraco na cama de ozônio etc.), mas que não pode ser prevista ou quantificada.

O ser humano é apontado como responsável ainda por todos os fatores que levam a população ao medo. A volatilidade das relações interpessoais, a prevalência dos interesses do mercado sobre os interesses políticos, a flexibilização da soberania estatal, que cede lugar aos interesses de uma economia mundial, a dependência dos países emergentes ao capital especulativo, a concentração de renda, todos esses são fatores que acometem a população mundial a diversos medos, todos eles relacionados à concepção subjetiva de risco: risco social, ambiental, alimentar, econômico, político, urbano etc.

Nesse contexto, ao Estado que antes era atribuída apenas a função de redistribuidor de riquezas em nome do valor da igualdade, agora é chamado a assumir também o papel de redistribuidor dos riscos, gerindo-os frente toda a sociedade, o que se faz em nome do valor da segurança. Essa mudança implica numa nova formulação do conceito de segurança social, que antes estava vinculada apenas à liberdade e à propriedade, esperando do Estado apenas uma 
abstenção estatal. No ambiente apresentado, a segurança se reformula para ganhar nova significação, relativa à prestação estatal de gestão dos riscos, sob todos os aspectos.

Essa evolução implica também numa modificação conceitual da ideia de solidariedade, a partir do entendimento de que todos devem contribuir igualmente para a preservação da ordem social, numa tentativa de reduzir as constantes incertezas e a inafastável sensação de insegurança social. Assim, exposto esse quadro, por meio da análise do julgamento da Ação Direta de Inconstitucionalidade $\mathrm{n}^{\circ}$ 3.105-DF, e dos Recursos Extraordinários $560.626,556.664$ e 559.882, foi possível visualizar com claridade como os novos anseios sociais têm repercutido no direito brasileiro e, mais especificamente, no direito tributário. Os julgados analisados demonstram a mudança substancial por que têm passado os princípios da solidariedade e da segurança jurídica, respectivamente.

Ao exigir-se do Estado uma postura de garantidor dos direitos sociais e de segurança em geral, o poder de tributar, responsável pelo financiamento das atividades estatais, acaba por ser utilizado como ferramenta para viabilizar esta nova tarefa, valendo-se, portanto, de novos valores. A solidariedade, no julgamento da ADI referida, foi levantada como a justificativa da manutenção de novo tributo, desconforme das competências tributárias definidas pelo poder constituinte originário, mas que se fazia necessário a evitar um colapso do sistema de seguridade social do país. O Supremo Tribunal Federal, ainda nesse julgamento, expôs também que o quadro contextual que impõe a referida medida é de ordem global, exigindo dos Estados novas formas de atuação.

Nos Recursos Extraordinários julgados em conjunto, o STF, dessa vez em nome da segurança jurídica, ao mesmo tempo em que reconheceu a inconstitucionalidade na arrecadação de tributos previdenciários, negou sumariamente a possibilidade de que tais valores fossem repetidos em favor dos contribuintes (cidadãos), em proteção à instituição da seguridade social. Esse posicionamento demonstra claramente como também tem se alterado o conteúdo e a extensão do princípio segurança jurídica, que historicamente está vinculado a uma proteção do indivíduo contra a arbitrariedade e a surpresa proveniente da ação do Estado.

Ao que se vê, o discurso utilizado pelos tribunais demonstra uma nova composição entre Estado e sociedade, que se reflete na legitimação social dada ao poder de tributar. Vê-se que não deve mais haver um suposto conflito de interesses entre cidadãos e Estado, uma vez que este tem como função garantir os interesses daqueles, havendo agora, na relação jurídica tributária, uma confluência horizontal de interesses e não mais uma tensão, resultante da verticalidade pela qual as espécies tributárias sempre foram impostas. 
Isso representa uma completa mudança na forma de compreender a atuação estatal e, de forma mais específica, de compreender a função teleológica e os valores que regem a compreensão do fenômeno jurídico-tributário no Brasil. Definitivamente, tem-se visto que esse ramo do direito está num processo de reconstrução de valores, o que implica numa reformulação dos seus institutos, numa nova forma de conceber a tributação e o poder de tributar. Acredita- se estar diante de um novo paradigma do Direito Tributário, mesmo que ainda incipiente. 


\section{REFERÊNCIAS}

ARRUDA JR., Edmundo Lima de. O Moderno e o Pós-Moderno no Direito: Reflexões Sobre um Neocolonialismo Juridicista. In: SOUTO, Cláudio; FALCÃO, Joaquim. Sociologia e Direito: Textos básicos para a Disciplina de Sociologia Jurídica. 2.ed. São Paulo: Pioneira Thomson Learning, 2002, pp. 245-254.

ATIENZA, Manuel. Constitucionalismo, globalización y derecho. Disponível em: http://www.fd.unl.pt/docentes_docs/ma/amh_MA_7783.doc.

ÁVILA, Humberto. Limites à Tributação com Base na Solidariedade Social. In: GRECO, Marco Aurélio; GODOI, Marciano Seabra. Solidariedade Social e Tributação. São Paulo: Dialética, 2005, p. 68-88.

BAUMAN, Zygmunt. Confiança e Medo na Cidade. Rio de Janeiro: Zahar, 2009, p. 16.

BAUMAN, Zygmunt. Em busca da política. Rio de Janeiro: Zahar, 1999.

BECK, Ulrich. La Sociedad Del Riesgo: Hacia una nueva modernidad. Barcelona: Paidós, 1998.

CALIENDO, Paulo. Direito Tributário e Análise Econômica do Direito: Uma visão crítica. Rio de Janeiro: Elsevier, 2009.

CARBONNIER, Jean. As Hipóteses Fundamentais da Sociologia Jurídica Teórica. In: SOUTO, Cláudio; FALCÃO, Joaquim. Sociologia e Direito: Textos básicos para a Disciplina de Sociologia Jurídica. 2.ed. São Paulo: Pioneira Thomson Learning, 2002, pp. 35-48.

Sociologia Jurídica. Coimbra: Livraria Almedina, 1979.

DURKHEIM, Émile. As Regras do Método Sociológico. São Paulo: Martin Claret, 2002. LIMA NETO, Manoel Cavalcante de. Direitos Fundamentais dos Contribuintes. Recife: Nossa Livraria, 2005.

MIRANDA ROSA, F. A.. Sociologia do Direito: O fenômeno jurídico como fato social. $17^{\mathrm{a}}$.ed. Rio de Janeiro: Jorge Zahar Editor, 2004.

RIBEIRO, Ricardo Lodi. A Segurança dos Direitos Fundamentais do Contribuinte na Sociedade de Risco. In: RIBEIRO, Ricardo Lodi. Temas de Direito Constitucional Tributário. Rio de Janeiro: Lumen Juris, 2009, pp. 43-67.

Constitucionalização do Direito Tributário. In: RIBEIRO, Ricardo Lodi.

Temas de Direito Constitucional Tributário. Rio de Janeiro: Lumen Juris, 2009, pp. 01-24.

Globalização, Sociedade de Risco e Segurança. Revista de Direito Administrativo, v. 246, p. 267-287, 2007. 
SANTOS, Boaventura de Sousa. Pela Mão de Alice. O Social e o Político na Pós-Modernidade. 10.ed. São Paulo: Cortez, 2005.

SOUTO, Cláudio; SOUTO, Solange. Sociologia do Direito: Uma visão substantiva. Porto Alegre: Sérgio Antonio Fabris Editora, 2003.

TREVES, Renato. Métodos de Pesquisa Empírica. In: SOUTO, Cláudio; FALCÃO, Joaquim. Sociologia e Direito: Textos básicos para a Disciplina de Sociologia Jurídica. 2.ed. São Paulo: Pioneira Thomson Learning, 2002, pp. 65-75.

VEYRETT, Yvette. Os Riscos: o homem como agressor e vítima do meio ambiente. São Paulo: Contexto, 2007.

1 ARRUDA JR., Edmundo Lima de. O Moderno e o Pós-Moderno no Direito: Reflexões Sobre um Neocolonialismo Juridicista. In: SOUTO, Cláudio; FALCÃO, Joaquim. Sociologia e Direito: Textos básicos para a Disciplina de Sociologia Jurídica. 2.ed. São Paulo: Pioneira Thomson Learning, 2002, pp. 245-254.

2 ATIENZA, Manuel. Constitucionalismo, globalización y derecho. Disponível em:

http://www.fd.unl.pt/docentes_docs/ma/amh_MA_7783.doc. Acesso em: 10 jan. 2015.

3 SANTOS, Boaventura de Sousa. Pela Mão de Alice. O Social e o Político na PósModernidade. 10.ed. São

Paulo: Cortez, 2005, pp. 80-83.

4 SAnTOS, Boaventura de Sousa. Pela Mão de Alice. O Social e o Político na PósModernidade. 10.ed. São

Paulo: Cortez, 2005, p. 86.

5 SANTOS, Boaventura de Sousa. Pela Mão de Alice. O Social e o Político na PósModernidade. 10.ed. São

Paulo: Cortez, 2005, pp. 83-87.

6 SANTOS, Boaventura de Sousa. Pela Mão de Alice. O Social e o Político na PósModernidade. 10.ed. São

Paulo: Cortez, 2005, p. 89.

7 SANTOS, Boaventura de Sousa. Pela Mão de Alice. O Social e o Político na PósModernidade. 10.ed. São

Paulo: Cortez, 2005, p. 91.

8 BECK, Ulrich. La Sociedad Del Riesgo: Hacia una nueva modernidad. Barcelona: Paidós, 1998.

9 VEYRETT, Yvette. Os Riscos: o homem como agressor e vítima do meio ambiente. São Paulo: Contexto, 2007, pp. 13-14. 
10 RIBEIRO, Ricardo Lodi. Globalização, Sociedade de Risco e Segurança. Revista de Direito Administrativo, v. 246, p. 267-287, 2007, p. 272.

11 VEYRETT, Yvette. Os Riscos: o homem como agressor e vítima do meio ambiente. São Paulo: Contexto, 2007, p. 11.

12 RIBEIRO, Ricardo Lodi. Globalização, Sociedade de Risco e Segurança. Revista de Direito Administrativo, v. 246, p. 267-287, 2007, p. 274.

13 BECK, Ulrich. La Sociedad Del Riesgo: Hacia una nueva modernidad. Barcelona: Paidós, 1998, p. 25.

14 ARRUDA JR., Edmundo Lima de. O Moderno e o Pós-Moderno no Direito: Reflexões Sobre um Neocolonialismo Juridicista. In: SOUTO, Cláudio; FALCÃO, Joaquim. Sociologia e Direito: Textos básicos para a Disciplina de Sociologia Jurídica. 2.ed. São Paulo: Pioneira Thomson Learning, 2002, pp. 245-254. p. 248.

15 BAUMAN, Zygmunt. Confiança e Medo na Cidade. Rio de Janeiro: Zahar, 2009, p. 16.

16 BECK, Ulrich. La Sociedad Del Riesgo: Hacia una nueva modernidad. Barcelona: Paidós, 1998, p. 56.

17 SAnTOS, Boaventura de Sousa. Pela Mão de Alice. O Social e o Político na PósModernidade. 10.ed. São

Paulo: Cortez, 2005, p. 91.

18 SAnTOS, Boaventura de Sousa. Pela Mão de Alice. O Social e o Político na PósModernidade. 10.ed. São

Paulo: Cortez, 2005, p. 91.

19 BECK, Ulrich. La Sociedad Del Riesgo: Hacia una nueva modernidad. Barcelona: Paidós, 1998, p. 56.

20 BAUMAN, Zygmunt. Em busca da política. Rio de Janeiro: Zahar, 1999, p. 56: “os governos não podem honestamente prometer aos cidadãos uma existência segura e um futuro garantido, mas podem, por ora, pelo menos eliminar parte da carga de ansiedade acumulada (e até lucrar com isso do ponto de vista eleitoral)".

21 Yvette Veyrett, em sua obra, descreve como os Estados Unidos tem atuado na previsão, proteção e reconstrução da sociedade frente aos riscos a que o país, de dimensões continentais, está sujeito. Menciona a criação de uma agência federal (FEMA) destinada a conhecer e controlar os riscos do país. Esse órgão tem a função de colher com profundidade dados concernentes às diversas áleas naturais possíveis na região, o que serve de valoroso banco de dados para empresas seguradoras, havendo clara integração entre conhecimento do risco, seu gerenciamento e a influência destes fatores na economia. Mais que isso, o próprio governo 
participa ativamente, estimulando a população a realizar contratos de seguro em determinadas regiões sujeitas a inundações, numa simbiose entre interesse público e econômico. VEYRETT, Yvette. Os Riscos: o homem como agressor e vítima do meio ambiente. São Paulo: Contexto, 2007, pp. 221-244.

22 ATIENZA, Manuel. Constitucionalismo, globalización y derecho. Disponível em:

http://www.fd.unl.pt/docentes_docs/ma/amh_MA_7783.doc. Acesso em: 10 jan. 2015.

23 NABAIS, José Casalta. Da sustentabilidade do Estado Fiscal. In: NABAIS, José Casalta; TAVARES DA SILVA, Suzana (Coord.). Sustentabilidade Fiscal em Tempos de Crise. Coimbra: Almedina, 2011. p. 21-22.

24 RODRIGUES DE SIQUEIRA, Marcelo. Os desafios do estado fiscal contemporâneo e a transparência fiscal. In: NABAIS, José Casalta; TAVARES DA SILVA, Suzana (Coord.). Sustentabilidade Fiscal em Tempos de Crise. Coimbra: Almedina, 2011. p. 134-135.

25 CALIENDO, Paulo. Direito Tributário e Análise Econômica do Direito: Uma visão crítica. Rio de Janeiro: Elsevier, 2009, pp. 84-90.

26 CALIENDO, Paulo. Direito Tributário e Análise Econômica do Direito: Uma visão crítica. Rio de Janeiro: Elsevier, 2009. p. 89.

27 ÁVILA, Humberto. Limites à Tributação com Base na Solidariedade Social. In: GRECO, Marco Aurélio; GODOI, Marciano Seabra. Solidariedade Social e Tributação. São Paulo: Dialética, 2005, p. 68-88. pp. 69-70.

28 Voto do Ministro César Peluso, na ADIn n³.105, pp. 99-110 (Grifo nosso).

29 TORRES, Ricardo Lobo. Legalidade Tributária e Riscos Sociais. In: Revista Dialética de Direito Tributário,

n. 59 , p. 99-112, 2000. p. 101.

30 TORRES, Ricardo Lobo. Legalidade Tributária e Riscos Sociais. In: Revista Dialética de Direito Tributário,

n. 59, p. 99-112, 2000. p. 102-103.

31 TORRES, Ricardo Lobo. Legalidade Tributária e Riscos Sociais. In: Revista Dialética de Direito Tributário,

n. 59, p. 99-112, 2000. p. 104-105.

32 TORRES, Ricardo Lobo. Legalidade Tributária e Riscos Sociais. In: Revista Dialética de Direito Tributário,

n. 59, p. 99-112, 2000. p. 104-105. 
33 ÁVILA, Humberto. Segurança Jurídica. Entre permanência, mudança e realização no Direito Tributário. 2. ed. São Paulo: Malheiros, 2012, p. 581.

34 LIMA NETO, Manoel Cavalcante de. Direitos Fundamentais dos Contribuintes. Recife: Nossa Livraria, 2005 , p. 37.

35 RIBEIRO, Ricardo Lodi. Constitucionalização do Direito Tributário. In: RIBEIRO, Ricardo Lodi. Temas de

Direito Constitucional Tributário. Rio de Janeiro: Lumen Juris, 2009, pp. 01-24. p. 10.

36 RIBEIRO, Ricardo Lodi. Constitucionalização do Direito Tributário. In: RIBEIRO, Ricardo Lodi. Temas de

Direito Constitucional Tributário. Rio de Janeiro: Lumen Juris, 2009, pp. 01-24. p. 09.

37 FOLLONI, André. Função Promocional do Direito e as Novas Exigências da Pesquisa Científica em Direito Tributário. In: MACEI, Demetrius Nichele; DIAS, Maria Tereza Fonseca; COUTINHO, João Hélio de Farias Moraes. Direito Tributário II: XXIII Congresso Nacional do CONPEDI. Florianópolis: CONPEDI, 2014, p. 131.

38 BOBBIO, Norberto. Da Estrutura à Função: Novos estudos de teoria do direito. Barueri: Manole, 2007, 101.

39 BOBBIO, Norberto. Da Estrutura à Função: Novos estudos de teoria do direito. Barueri: Manole, 2007, 101.

40 RIBEIRO, Ricardo Lodi. A Segurança dos Direitos Fundamentais do Contribuinte na Sociedade de Risco. In:

RIBEIRO, Ricardo Lodi. Temas de Direito Constitucional Tributário. Rio de Janeiro: Lumen Juris, 2009, pp.

43-67. p. 62. 